EESTI NSV TEADUSTE AKADEEMIA TOIMETISED, 28. KOIDE GEOLOOGIA. 1979, NR. 4

ИЗВЕСТИЯ АКАДЕМИИ НАУК ЭСТОНСКОИ ССР. ТОМ 28 ГЕОЛОГИЯ. 1979, № 4

\title{
БИОСТРАТИГРАФИЧЕСКАЯ ХАРАКТЕРИСТИКА ДОННЫХ ОТЛОЖЕНИЙ ЦЕНТРАЛЬНОГО И ЮЖНОГО РАЙОНОВ БАЛТИКИ
}

Геологические исследования последних лет показывают, что для стратификации и датирования донных отложений Балтики наиболее пригоден спорово-пыльцевой анализ, дополненный результатами диатомового анализа.

Нами изучены две колонки донных отложений Балтики - одна из глубоководного района Гданьской бухты (№ 1403), другая из северной части Восточно-Готландской впадины (№ 1399). Образцы взяты сотрудниками Атлантического отделения Института океанологии АН СССР (АО ИОАН) с научно-исследовательского судна «Профессор Добрынин» ударными вибропоршневыми трубками соответственно с глубин воды 88 и 158 м (рис. 1). Отобранные колонки после- и позднеледниковых отложений (мощностью 590 и 750 см) содержат сравнительно много древесной и травянистой пыльцы и спор хорошей сохранности.

Состав колонки Гданьской бухты (№ 1403) следующий:

0-49 cм — ил алевритово-пелитовый, обогащенный органическим веществом, с запахом сероводорода;

49-76 см - ил тонкополосчатый, обогащенный органическим веществом;

76-180 cм - глина тонкополосчатая серая, с включениями гидротроилита;

180 - 258 см - глина розовато-серая, со слабой микрослоистостью;

258-281 cм - (по четкой границе) глина темно-серая, слабо полосчатая, с включениями гидротронлита;

$281-478$ cм - глина микрослоистая, с прослойками гидротроилита;

478-521 см - глина микроленточная, с включениями гидротроилита, в основании алевритовая прослойка мощностью 3 -4 м. .

Отложения приледниковых озер и Балтийского ледникового озера представлены ленточными и микрослоистыми глинами мощностью 240 см в интервале 350 - 590 см. По составу пыльцы и спор весь отрезок глинистых отложений оказался одинаковым и характеризуется содержанием пыльцы сосны $(60-70 \%)$, березы $(20-40 \%)$, ольхи и ели (до $8 \%$ ). Основные сведения о климате и растительном покрове дает состав травянистых растений и спор. В интервале $350-355$ см пыльца Artemisia и Chenopodiaceae составляет соответственно до 60 и $22 \%$. Ниже, в интервале $480-530$ см, обнаружено много пыльцы Cyperaceae 


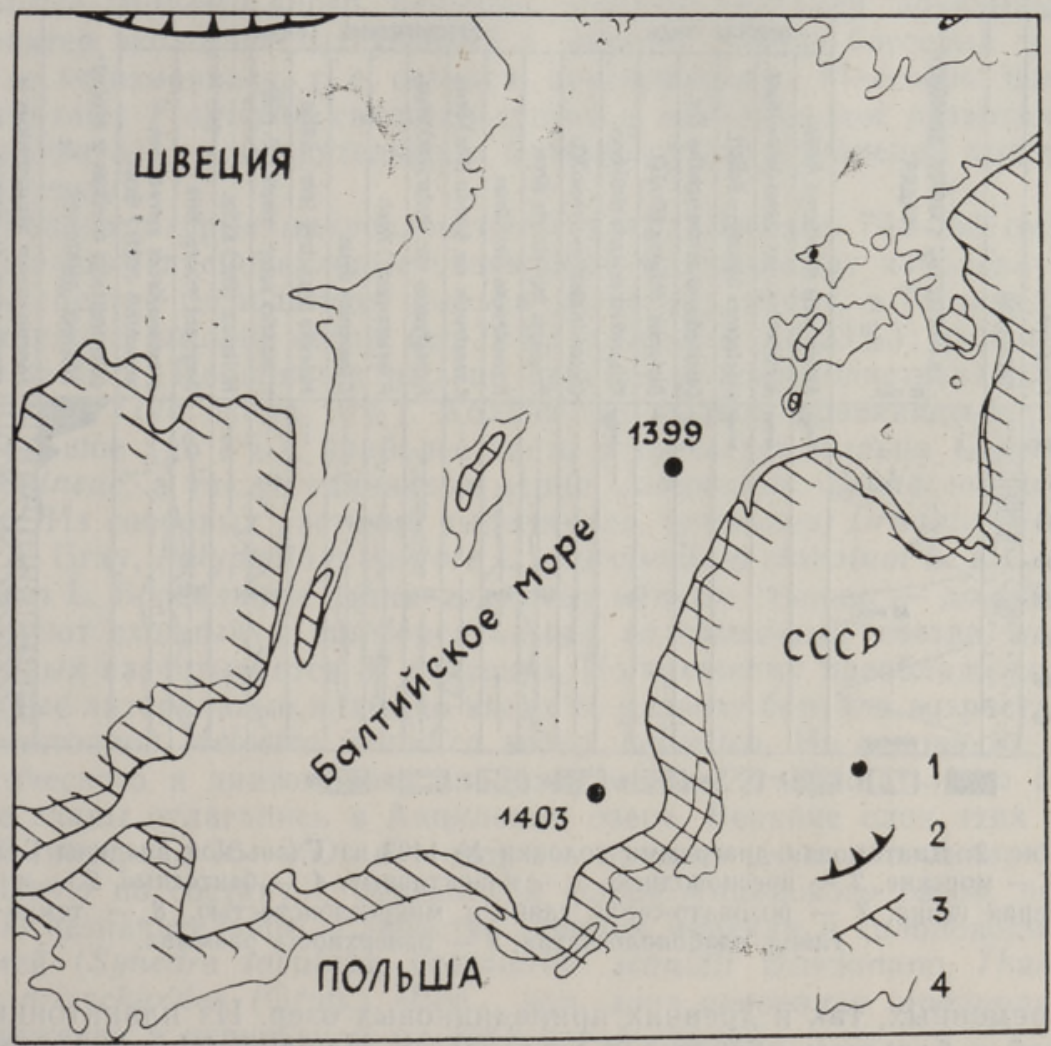

Рис. 1. Береговая линия пребореального Иольдиевого моря около 10000 лет назад (Sauramo, 1958, с нашими дополнениями). 1 - местоположение изученных буровых скважин; 2 - край ледника; 3 - береговая линия и суша в пребореале, 4 - береговая линия современного моря.

и Gramineae, а количество тундровых споровых растений очень незначительно. Присутствие пыльцы травянистых растений и спор позволяет предположить существование здесь донных отложений аллереда. Как известно, спорово-пыльцевые спектры среднего дриаса содержат мало пыльцы травянистых растений и спор из-за слаборазвитой растительности на побережье Балтики в этот период. В позднеледниковых отложениях этой диаграммы отмечается незначительная роль пыльцы кустарниковых берез (Betula humilis Schrank. и B. nana L.) - в интервале $350-355 \mathrm{~cm}$ до $30 \%$, а в интервалах $480-485 \mathrm{~cm}, 520$ и $530 \mathrm{~cm}$ еще меньше (12, и $15 \%)$.

Позднеледниковые отложения данной колонки, относимые нами к верхнему дриасу, прослеживаются в интервале $350-478$ см, а залегающая ниже ленточная глина принадлежит, очевидно, к аллереду. В пользу такого разделения отложений говорят их литология и состав диатомовых, установленный только в интервале 425-433 см (рис. 2). На этой глубине колонки содержание створок относительно высокое 53,5 тыс. в пересчете на 1 г воздушно-сухого осадка. Установлено 29 видов и разновидностей пресноводных диатомей. Основу диатомового комплекса составляют литоральные диатомеи, развивающиеся на мелководьях. Доминируют перифитонная Opephora martyi Heib., а также Achnanthes clevei Grun., Cocconeis disculus (Schum.) Cl. и Navicula scutelloides W. Sm., т. е. виды, характерные для песчаной литорали как 


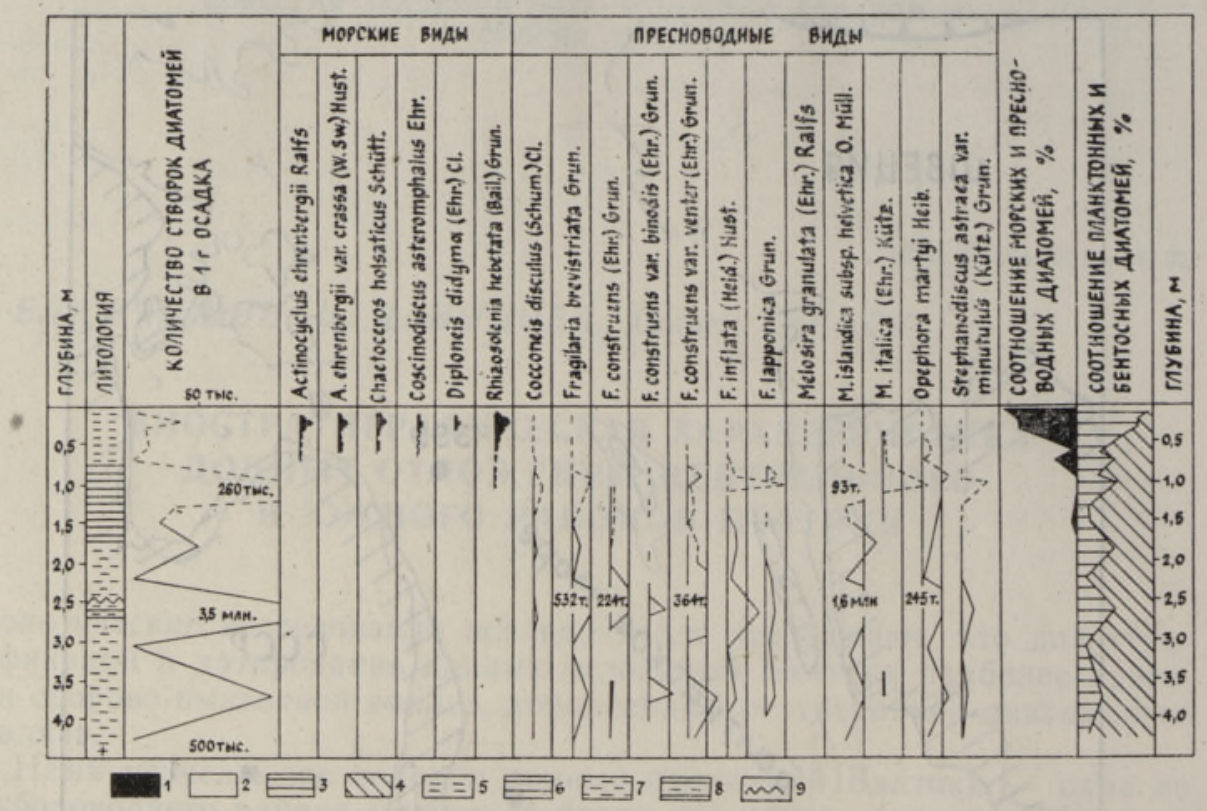

Рис. 2. Диатомовая диаграмма колонки № 1403 из Гданьской впадины Балтики. 1 - морские, 2 - пресноводные, 3 - планктонные, 4 - бентосные, 5 - ил, 6 серая глина, 7 - розовато-серая глина с микрослоистостью, 8 - темно-сераг глина, слабополосчатая, 9 - поверхность размыва.

современных, так и древних приледниковых озер. Из планктонных диатомей в большом количестве встречается Melosira islandica subsp. helvetica O. Müll., типичная для планктона олиготрофных озер Финляндии и Скандинавии, Северо-Запада СССР и Северной Америки, в прошлом широко распространенная в приледниковых озерах. Описанная диатомовая флора свидетельствует о формировании отложений в пресноводном олиготрофном бассейне со значительным влиянием мелководий.

Дриасовые отложения переходят в пребореальные, характер осадка при этом существенно не меняется. В то же время верхняя граница пребореальной осадочной толщи мощностью около 1 м в интервале 258 350 см очень отчетливая. В общем составе пребореальных отложений господствует пыльца древесных растений, а присутствие травянистых растений и спор уменьшается до $5 \%$. В составе древесных пород доминирует сосна (55\% пыльцы), довольно много березы $(40 \%)$ и появляется ольха $(5 \%)$. Содержание пыльцы кустарниковых берез не превышает $10 \%$. Из пыльцы травянистых растений в небольшом количестве $(5 \%)$ отмечена пыльца Artemisia, Chenopodiaceae и Cyperaceae.

Такой состав пыльцы и спор указывает на образование темно-серой и отчасти микрослоистой глины, по-видимому, в пребореале. В этой толще численность диатомей высокая - до 3,5 млн. створок на 12 осадка, что является максимумом для всей колонки, при этом видовое разнообразие их невелико. Обнаружены 35 таксонов пресноводных диатомей и осколки створок морского вида Melosira sulcata (Ehr.) Kütz. Преобладают литоральные диатомеи Opephora martyi и большая группа Fragilaria. Из последних особенно обильны Fragilaria brevistriata Grun., F. construens (Ehr.) Grun. с разновидностями и F. inflata (Heid.) Hust. Среди планктонных диатомей по-прежнему превалирует 
Melosira islandica subsp. helvetica. Состав диатомей показывает, что характер экологических условий в данном районе бассейна в пребореале не изменился, т. е. остался пресноводным. Массовое появление эпифитных Fragilaria свидетельствует о значительном развитии в нем макрофитов, а следовательно, о большем распространении прибрежных мелководий.

Розовато-серые микрослоистые глины (интервал 76 -258 cм), перекрывающие пребореальные отложения, принадлежат к бореалу. В общем спектре господствует пыльца древесных пород, в составе которой доминирует пыльца сосны (до $76 \%$ ) и березы (до $23 \%$ ); пыльцы ольхи свыше $10 \%$. Появляется пыльца лещины и широколиственных (сумма Ulmus и Tilia около 10\%). Количество пыльцы травянистых растений небольшое (до 8\%), наиболее часто встречается пыльца Cyperaceae и Gramineae, а также единичные зерна Compositae, Typhaceae и Filipendula. Из споровых растений выделяются, например, Dryopteris thelypteris A. Gray, Polypodium vulgare L., Lycopodium clavatum L. и L. complanatum L. Бореальные глины содержат меньше створок - до 470 тыс. и имеют сходный с пребореальными отложениями состав диатомей, которых насчитывается 37 таксонов. По-прежнему преобладают пресноводные литоральные виды, но вверх но разрезу бореала возрастает роль планктонной Melosira islandica subsp. helvetica. На основании палинологического и диатомового анализов можно утверждать, что бореальные глины отлагались в Анциловом озере. Верхние слои этих отложений (интервал 76-150 cм) содержат пресноводную диатомовую флору, близкую по составу к бореальной флоре Анцилового озера, но имеющую незначительное количество створок морских и солоноводных диатомей (Synedra tabulata, Fragilaria schulzii Brockmann, Thalassionema nitzschioides (Grun.) Hust., что дает основание предполагать их отложение в переходной мастоглойевой стадии.

Лежащие выше по разрезу илы (интервал 58-76 cм) принадлежат к атлантике. В спектрах установлено сравнительно большое количество пыльцы широколиственных (до $18 \%$ ), особенно дуба, а также лещины (до $16 \%$ ) и ольхи (до $17 \%$ ). Содержание пыльцы ели достигает $10 \%$, Carpinus - 2\%. В атлантических донных отложениях определено много спор папоротников лесного типа. Состав разнотравья относительно сложен.

В нижней части иловой толщи, сформировавшейся в атлантике, содержание створок морских диатомей доходит до $34 \%$. Наиболее часто встречаются Rhizơsolenia hebetata (Bail.) Gran., Actinocyclus ehrenbergii Ralfs. и Diploneis didyma (Ehr.) Cl., а также характерные для солоноводных стадий Балтики мезогалобы Thalassiosira baltica (Grun.) Ostf., Coscinodiscus asteromphalus Ehr. и Synedra tabulata (Ag.) Kütz. Состав пресноводных диатомей остается прежним, причем вверх по разрезу поступление пресноводных диатомей сокращается.

В спектрах вышележаших илов (интервалы 50-58 cм) меньше пыльцы широколиственных, ольхи, сильно сокращается количество пыльцы лещины, а соответственно, увеличивается доля пыльцы березы и сосны. Содержание пыльцы ели достигает $13 \%$. В составе пыльцы травянистых растений продолжает расти роль Gramineae и Cyperaceae за счет уменьшения количества Artemisia, Chenopodiaceae и разнотравья.

В рассматриваемых илах содержание створок диатомей доходит до 13 тыс., морские диатомеи составляют до $27 \%$, причем наиболее массовы Rhizosolenia hebetata и Actinocyclus ehrenbergii et var. crassa (W. Sm.) Hust., а также Chaetoceros holsaticus Schütt. Количество ство- 


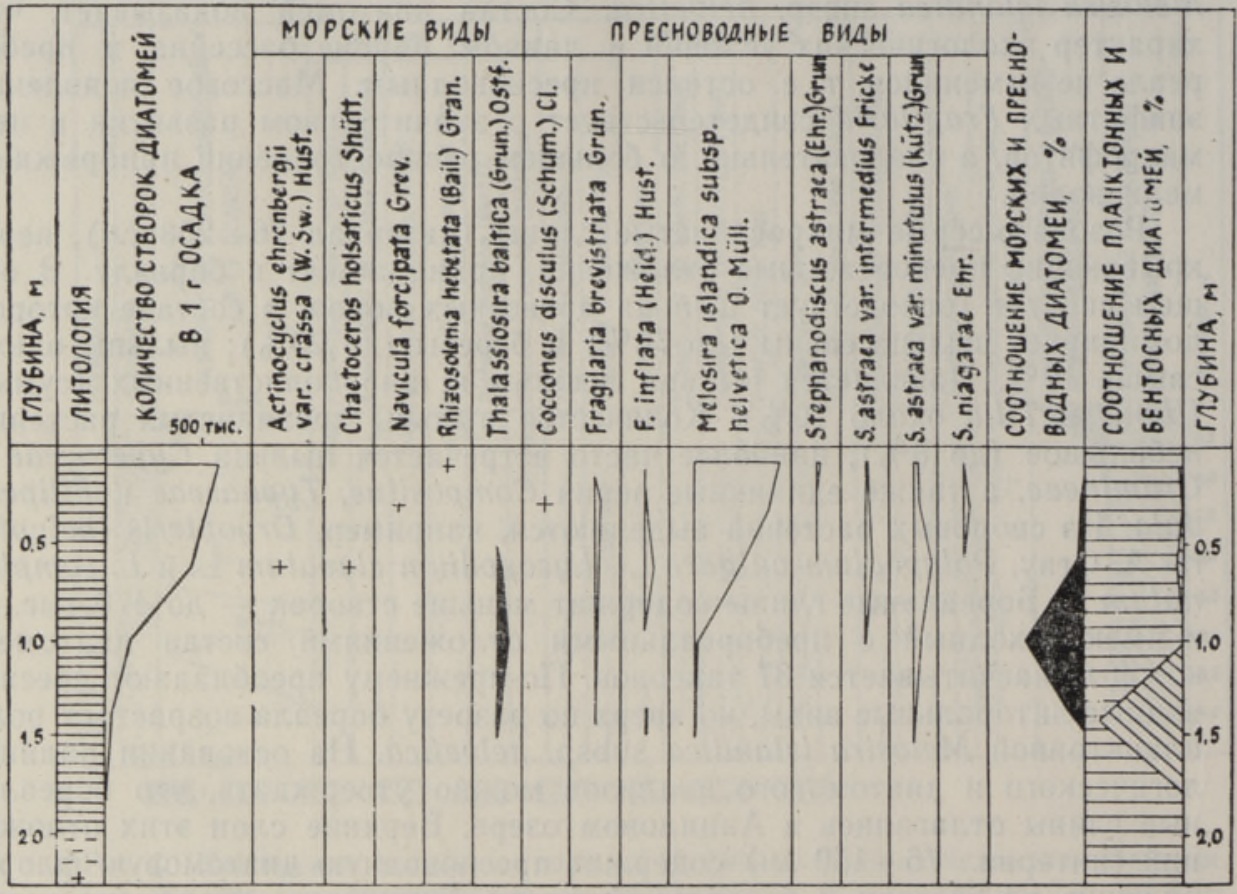

Рис. 3. Диатомовая диаграмма колонки № 1399 из Восточно-Готландской впадины Балтики. Условные обозначения см. на рис. 2.

рок пресноводных диатомей по-прежнему велико. Осаждение этих суббореальных донных отложений происходило в конце стадии Литоринового моря или в начале распространения Лимниевого моря.

Верхние $50 \mathrm{~cm}$ илов относятся к субатлантике. Соответствующие пыльцевые спектры по составу сходны со спектрами суббореальных отложений. Отмечаются незначительное уменьшение содержания пыльцы ели и небольшое количество пыльцы Fraxinus, Carpinus и Fagus.

Этот слой илов содержит морскую диатомовую флору. Численность створок не превышает 35 тыс. Морские диатомеи составляют $74 \%$ из створок, а в верхнем горизонте даже $91 \%$. Доминируют мезогалобы Actinocyclus ehrenbergii cf. var. crassa, Chaetoceros holsaticus и Rhizosolenia hebetata. Пресноводные диатомеи встречаются в виде незначительной примеси. Следует отметить, что в нижней части субатлантических илов превалируют створки эугалобов (до $39 \%$ от общего содержания диатомей), а вверх по разрезу увеличивается роль мезогалобов (от 35 до 63\%). Поступление створок пресноводных диатомей в изученный нами район Балтики в это время резко сокращается.

Колонка Восточно-Готландской впадины (№ 1399) имеет следующее строение:

0-200 cм - серая тонкая гомогенная глина с включениями гидротроилита;

200-400 см - розовато-серая глина с тонкой полосчатостью;

400-520 см - микроленточная глина;

520-710 cм - ленточная глина, обогащенная карбонатами;

710-754 см - ленточная глина с преобладанием карбонатных лент.

Для спорово-пыльцевого и диатомового анализов (рис. 3) отобрано 
соответственно 19 и 20 образцов, из последних только 7 (интервал 0 -220 cм) содержали диатомовую флору. По характеру донных отложений, палинологическим данным и результатам изучения диатомей верхняя половина этой колонки разделяется на 3 части, сформировавшиеся в позднем дриасе (интервал 200-220 см), пребореале (50$200 \mathrm{~cm})$ и бореале $(0-50 \mathrm{~cm})$. Вниз по разрезу до глубины $520 \mathrm{~cm}$ продолжаются верхнедриасовые микроленточные глины. Еще глубже возраст отложений точно не определен, и они условно отнесены к дриасу, представленному ленточными глинами. Верхнедриасовые глины общей мощностью 320 см характеризуются сравнительно высоким содержанием пыльцы травянистых растений (до $38 \%$ ) и спор (до $22 \%$ ). В составе пыльцы древесных пород преобладает пыльца сосны (до $82 \%$ ) и березы (до 25\%), последняя представлена Betula humilis и B. nana (до $50 \%$ ). Содержание пыльцы ели около $7 \%$, пыльца ольхи встречается спорадически. В составе пыльцы травянистых растений, как обычно, обнаружена пыльца Artemisia (до $50 \%$ ), Chenopodiaceae (до $35 \%$ ) и разнотравья. Из спор обнаружены главным образом споры Bryales и Lycopodiales, а также единичные зерна Polypodiaceae и Sphagnales. В верхней части тонкополосчатых глин верхнедриасового возраста обнаружены единичные створки пресноводной планктонной Melosira islandica subsp. helvetica, численность которой не превышает 1,5 тыс. в 1 г осадка. Осаждение описанных донных отложений в виде микроленточных глин происходило в Балтийском ледниковом озере.

Отложения Иольдиевого моря прослеживаются в данной колонке в виде гомогенных серых глин полутораметровой мощности. Такая мощность свидетельствует о быстрой седиментации осадков в этот довольно короткий начальный период голоцена. В общем составе пыльцы и спор господствует пыльца древесных пород (до $86 \%$ ), среди них доминирует пыльца сосны (до $55 \%$ ) и березы (до $23 \%$ ), найдено немного пыльцы ольхи, широколиственных пород и ели. В составе пыльцы травянистых растений отмечается незначительное количество пыльцы Artemisia, Chenopodiaceae, Gramineae и Cyperaceae. Найдены единичные зерна водных растений Nymphaceae и Typhaceae. Содержание спор сфагновых мхов и папоротников невелико во всех образцах глин.

Рассматриваемая пребореальная толща глин по составу диатомей неоднородна, и ее можно разделить на 3 части. В нижней части (интервал 130-200 cм) диатомеи малочисленны - до 15 тыс. створок, из которых около $90 \%$ составляют пресноводные, преимущественно бентосные виды. Наиболее часто встречаются эпифитные Cocconeis disculus var. diminuta Schum., Fragilaria inflata и планктонная Melosira islandica subsp. helvetica, обитавшие ранее в Балтийском ледниковом озере. Солоноводные и морские виды составляют только $10 \%$ створок, среди них отмечается прежде всего Thalassiosira baltica. Эти отложения сформировались в начальной стадии осолонения пребореальной Балтики, когда морские воды проникли в котловину через возникшие Средне-Шведские проливы.

Вверх по разрезу (интервал 90-130 см) содержание створок возрастает до 110 тыс. Доминируют морские диатомеи, составляющие в сумме $62 \%$ створок, наиболее массовая из них Thalassiosira baltica. В большом количестве встречается также пресноводный планктонный Stephanodiscus astraea var. minutulus. Эти отложения соответствуют максимальной стадии осолонения Иольдиевого моря. В верхней части пребореальных глин (интервал 50-90 см) численность диатомей возрастает до 435 тыс. за счет массового накопления пресноводных планктонных пелагических диатомей Melosira islandica subsp. helvetica, 
Stephanodiscus astraea var. minutulus et var. intermedius и др. Одновременно в диатомовом комплексе присутствуют в значительных количествах Thalassiosira baltica и другие мезогалобы: Actinocyclus ehrenbergii var. crassa и Chaetoceros holsaticus. Морские диатомеи составляют около $6 \%$ из общего содержания створок. Эти отложения образовались в стадии опреснения воды Иольдиевого моря, когда воды Мирового океана почти не проникали в Балтийскую котловину вследствие изостатического поднятия земной коры в районе Средне-Шведского пролива.

Осаждение самых верхних слоев глин (интервал $0-50$ см) происходило в бореале. В соответствующих спорово-пыльцевых спектрах увеличивается количество пыльцы сосны до $61 \%$. Пыльца березы составляет 16 , пыльца ольхи - 11 , широколиственных -6 , ели $-7 \%$; среди кустарниковых довольно много $(18 \%)$ лещины. Резко увеличивается количество пыльщы травянистых растений Gramineae и Cyperaceae (обоих почти до $50 \%$ ).

В начале бореала закрылся Средне-Шведский пролив в Мировой океан и в пределах котловины Балтики возникло Анциловое озеро. Об этом свидетельствует характер типично пресноводной флоры, установленный в бореальных глинах в интервале $0-50$ см. Численность диатомовых достигает 700 тыс. створок в 1 г осадка, при этом более $80 \%$ из них составляет Melosira islandica subsp. helvetica. Характерны для этих глин также планктонные Stephanodiscus astraea (Ehr.) Grun. с разновидностями и St. niagarae Ehr., Melosira distans var. alpigena (Ehr.) Kütz. и M. italica. Несомненно, представленные диатомеи свидетельствуют об осаждении глин в условиях крупного пресноводного олиготрофного озера.

Приведенный в настоящей работе материал показывает, что результаты биостратиграфического изучения донных отложений колонки № 1403 хорошо сопоставимы с данными колонок, изученных нами ранее из района Южной Балтики (Кессел и др., 1973; Блажчишин и др., 1974). Подтверждается предположение, что Гданьская впадина в пребореальное время представляла собой пресноводный водоем со значительными глубинами в центральной части и заросшими макрофитами прибрежными мелководьями, отграниченный от основной акватории Балтики более протяженным в пребореале на запад Самбийским полуостровом. Колонка № 1403 взята несколько севернее этого полуострова, характер и содержание диатомей в пребореальных отложениях свидетельствуют о том, что к северу отсюда прибрежные районы Иольдиевого бассейна были преснымн.

Результаты биостратиграфического анализа колонки № 1399 хорошо сопоставляются с данными колонок № 782 (Блажчишин и др., 1974) и 2119 (Кессел и др., 1973; Блажчишин и др., 1975), взятых также в Восточно-Готландской впадине. Малое количество данных не позволило в свое время верно интерпретировать в колонке № 782 возраст трех выделенных авторами интервалов (Блажчишин и др., 1974, с. 120 , рис. 1). Возраст отложений первого интервала $(260-337$ см) определяется теперь как верхнедриасовый, второго $(60-260$ см) - как бореальный и третьего $(0-60 \mathrm{~cm})$ - от субатлантического до суббореального. В колонке № 2119 уверенно подтверждается произведенное ранее подразделение и уточняется возраст отложений бореального интервала, осаждение которых происходило в Мастоглойевом море. Распространение этого моря связывается с конечной частью второй половины бореала. 
ЛИТ Е Р А У Р А

Блажчишин А. И., Давыдова Н. Н., Кв асов Д. Д., Хомутов а В. И. Спорово-пыльцевой и диатомовый анализ четырех колонок донных отложений южной и центральной Балтики. - В кн.: Baltica. Вильнюс, 1974, т. 5, с. $119-126$.

Бл а жчишин А. И., Д а выдов а Н. Н., К ес сел Х. Я. О поздне- и послеледниковых отложениях глубоководных впадин Балтики. - В кн.: История озер в голоцене. Л., 1975 , с. $55-62$.

К ессел Х. Я., Да выдов а Н. Н., Блаж чиш ин А. И. Пыльца и диатомовые из колонок глубоководных впадин Балтики. - Изв. АН ЭССР. Хим. Геол,, 1973, т. 22 , № 4 , с. $345-354$.

S a uramo, M. Die Geschichte der Ostsee. - Ann. Acad. Sci. Fennicae. Sarja A. III. Geologica-Geographica, 1958, 51.

\section{Институт геологии \\ Академии наук Эстонской ССР \\ Поступила в редакцию \\ $7 /$ V 1979}

Атлантическое отделение Института океанологии

Академии наук СССР

Ннститут озероведения Академии наук СССР

\section{A. BLAZTSISIN, N. DAVODOVA, Helgi KESSEL}

\section{LÄANEMERE KESK- JA LOUNAOSA PÖHJASETETE BIOSTRATIGRAAFILINE ISELOOMUSTUS}

Gdanski lahe süvaveelise piirkonna ja Ida-Gdanski süviku põhjaosa puuraukude andmeil on esitatud põhjasetete litoloogiline iseloomustus (A. Blažtšišin), stratigraafiline liigestus ja vanus õietolmuanalüüside pōhjal (H. Kessel). Diatomeekomplekside iseloomu ja esinemise alusel on selgitatud Läänemere eri staadiumide paleoökoloogilisi tingimusi ja pōhjasetete kujunemise hüdrodünaamilisi iseärasusi (N. Davōdova).

\section{A. BLAZHTSHISHIN, N. DAVYDOVA, Helgi KESSEL}

\section{BIOSTRATIGRAPHY OF BOTTOM SEDIMENTS OF CENTRAL AND SOUTH BALTIC}

Two boring cores of bottom sediments of the Baltic - one from deep-water Gdansk Bay (N 1403) and the other from the northern part of the East-Gotland depression ( $\mathrm{N}$ 1399) have been studied. On the basis of pollen and spore analyses (H. Kessel), the lithological character (A. Blazhtshishin), stratigraphic division and dates of bottom sediments are presented. Palaeoecological conditions in different water basins of the Baltic, and hydrodynamic processes connected with sedimentation in the deepwater depression of the basin have been elucidated according to the occurrence and character of diatom complexes (N. Davydova).

In the boring core of bottom sediments of Gdansk depression, the following stratigraphic zones corresponding to the stages of the developmerit of the Baltic are distinguished: Late-Glacial - the Great Ice Lake and the Baltic ice Lake, Preboreal - the Yoldia Sea, Boreal - the Ancylus Lake, Atlantic - the Mastogloia Sea and the Littorina Sea, Subboreal and Subatlantic - the Limnea Sea. The bottom sediments of East Gdansk depression represent the Late Dryas, Preboreal and Boreal age. The diatoms indicate the salinity, temperature and depth in the Baltic Ice Lake, the Yoldia Sea and the Ancylus Lake, accordingly.

The data of biostratigraphic investigation of the boring cores from Gdansk Bay are in good agreement with those obtained by earlier studies of the South Baltic. They all confirm the supposition that in the Preboreal Yoldia Sea, the Gdansk Bay represented a coastal region of a fresh-water basin of considerable depth. The determination of the phases of primary occurrence of salt water, maximal distribution and regression of the Yoldia Sea in the Preboreal, and the corresponding characteristics of their diatom flora in bottom sediments of the East-Gotland depression are also of importance. 